\title{
Patients with Constipation and Related Factors
}

\author{
Emine Yurdakul Ertürk ${ }^{1}$, Onur Yalçın ${ }^{2}$ \\ ${ }^{1}$ Department of Pediatrics, Faculty of Medicine, Ordu University, Ordu, Turkey \\ ${ }^{2}$ Department of Pediatric Surgery, Faculty of Medicine, Ordu University, Ordu, Turkey. \\ Received: 19 Februvary 2019, Accepted 18 March 2019, Published online: 28 April 2019 \\ (C) Ordu University Institute of Health Sciences, Turkey, 2019
}

\begin{abstract}
Objectives: Constipation is a widespread public health problem throughout the world and is commonly seen in the childhood period. The aim of this study is to assess the etiologic causes, clinical features and factors related to constipation among cases attending with constipation complaints.

Methods: The files and automation records of 162 cases aged from one month to 18 years attending the pediatric health and diseases clinic with the complaint of constipation from January 2018 to January 2019 were retrospectively investigated.

Home accidents were self-reported and questioned for the previous year. We developed a composite index to assess the overall housing conditions. Housing conditions were accepted "inadequate" if the score was below the median. We developed a logistic regression model to predict the housing-related factors in accidents.

Results: The mean age of cases included in the study was 51,1 $\pm 40,8$ months (2-192 months), with 53,1\% of patients $(n=86)$ in the one month-3 years age interval. Of cases, $62.3 \%$ were female and $37.7 \%$ were male. Toilet training had been given to $56.8 \%$ of cases, with mean age of toilet training $2 \pm 0.5$ years. Fiber intake was insufficient in $72,2 \%$, while fluid intake was insufficient for $84,5 \%$. Of patients, $56,2 \%$ ( $n=91$ ) had begun supplementary nutrition early (before 6 months). Of cases, 22,8\% had developmental retardation, while 13\% $(n=21)$ had urinary tract infection as an additional accompanying problem. The most common accompanying complaints were abdominal pain and bleeding while defecating. In 39\% of patients, there was family history of constipation. The functional constipation rate was $90.1 \%$, while $1.9 \%$ had hypothyroidism, $1,9 \%$ had anal stenosis, $1,9 \%$ had medication use, 1,2\% had Hirschprung disease, 1,2\% had hypopotassemia, 1,2\% had hypercalcemia and one case had vitamin D intoxication identified.

Conclusion: Constipation is associated with factors like toilet training age, beginning supplementary food early and insufficient fiber and fluid amounts in diet. It may cause growth development delay, urinary system infections and behavior problems.

Key words: Child, constipation, etiology
\end{abstract}

Suggested Citation: Yurdakul Ertürk E, Yalçın O. Patients with Constipation and Related Factors. Middle Black Sea Journal of Health Science, 2019; 5(1): 1-5.

Address for correspondence/reprints:

Emine Yurdakul

Telephone number: +90 (505) 3892771

E-mail: eyurdakul52@hotmail.com

DOI: $10.19127 / \mathrm{mbsjohs.529445}$

\section{Introduction}

Constipation is a common complaint in the childhood period. It forms $3 \%$ of attendances at general pediatric clinics and $25 \%$ of attendances at pediatric gastroenterology clinics (Taitz et al.,1986; Loening, 1993). Apart from the neonatal period, $90-95 \%$ of cases have no organic cause identified and these patients receive functional constipation diagnosis (Baker et al., 1999; Benninga, 2004). There are many factors underlying functional constipation like fiber-poor nutrition, problems during toilet training and 
holding feces (Loening, 1993; Benninga, 2004; Rajindrajith and Devanarayana, 2011). In our study, we aimed to assess the sociodemographic data, etiologic causes and factors related to constipation among pediatric patients attending due to constipation.

\section{Methods}

The study included patients aged from one month to 18 years attending Ministry of Health Ordu University Education-Research Hospital Pediatric Health and Diseases Clinic from January 2018 to January 2019 with complaint of constipation. Data for 162 patients with full information accessed in file and automation records were retrospectively investigated. The patient age, gender, initial complaint, age of toilet training, onset time of complaints, duration of breastfeeding, time of starting supplementary food, fiber and fluid amounts in diet, duration of complaints, growth development, physical examination findings, family history and laboratory parameters were assessed. Constipation was diagnosed according to Rome III criteria (Hyman et al., 2006; Rasquin et al., 2006).

A statistical package program was used for statistical analysis. Descriptive analysis of assessment results was given as numbers and percentage for categorical variables and as mean \pm standard deviation, minimum and maximum for numerical variables.

\section{Results}

The number of cases included in the study was 162 , with 101 female $(62,3 \%)$ and 61 males $(37,7 \%)$. The mean age of cases was $51.1 \pm 40.8$ months (2192 months), with $53.1 \%(\mathrm{n}=86)$ in the 1 month-3 years age interval (Table 1$)$.

Table 1. Distribution of cases with constipation according to age group.

\begin{tabular}{ll}
\hline Age group & $(\mathbf{\%}) \mathbf{n}$ \\
\hline 1month-3years & $(53,1 \%) 86$ \\
4-6years & $(24,7 \%) 40$ \\
$\geq 7$ years & $(22,2 \%) 36$ \\
\hline
\end{tabular}

Toilet training had been given to 92 cases $(56,8 \%)$, with mean age of toilet training $2 \pm 0.5$ years. Of cases, $62(38,3 \%)$ had duration of constipation less than 2 months, while $100(61,7 \%)$ had constipation for longer than 2 months. When the fiber and fluid intake of cases included in the study was investigated, $27,8 \%(n=45)$ had sufficient fiber intake and $72,2 \%(n=117)$ had insufficient fiber intake, while $15,5 \%(\mathrm{n}=25)$ had sufficient fluid intake and $84,5 \%(n=137)$ had insufficient fluid intake. Of patients, 56,2\% (n=91) had begun supplementary food early (before 6 months). When patients are assessed in terms of developmental retardation, $37(22,8 \%)$ had developmental retardation, while $125(77,2 \%)$ did not. Of patients, $13 \%(\mathrm{n}=21)$ had urinary tract infection as an additional accompanying problem.

When the main complaints of patients with constipation are assessed, 49 of the 162 cases $(30,1 \%)$ had abdominal pain, $16(9,8 \%)$ had bleeding while defecating, $15(9,2 \%)$ had fecal incontinence and $11(6,7 \%)$ had abdominal distension.

When cases are assessed in terms of constipation among family members, 99 (61\%) had no history of constipation in the family, while 63 (39\%) had family history of constipation. The most common family member with constipation history was the mother for $19,1 \%(\mathrm{n}=31)$.

It was identified that 146 cases $(90,1 \%)$ had functional constipation, while $16(9,9 \%)$ had an organic cause. Organic causes identified for cases included hypothyroidism for three cases, anal stenosis for three cases, medication use for three cases, Hirschprung disease for two cases, hypopotassemia for two cases, hypercalcemia for two cases and vitamin D intoxication for one case (Table 2).

Table 2. Aetiology of constipation

\begin{tabular}{ll}
\hline Etiology & \multicolumn{1}{c}{$(\boldsymbol{\%}) \mathbf{~ n}$} \\
\hline Functional & $(90,1 \%) 146$ \\
Organic & $(9,9 \%) 16$ \\
Hypothyroidism & $(1,9 \%) 3$ \\
Anal stenosis & $(1,9 \%) 3$ \\
Drugs & $(1,9 \%) 3$ \\
Hirschprung disease & $(1,2 \%) 2$ \\
Hypokalemia & $(1,2 \%) 2$ \\
Hypercalcemia & $(1,2 \%) 2$ \\
Vitamin D intoxication & $(0,6 \%) 1$ \\
\hline
\end{tabular}

Of children with constipation, $17,3 \%(\mathrm{n}=28)$ bit their nails, 8,6\% $(\mathrm{n}=14)$ sucked their fingers, $2.5 \%$ $(\mathrm{n}=4)$ stuttered, 1,9\% $(\mathrm{n}=3)$ bit their nails and sucked their fingers and $0,6 \%(n=1)$ sucked their fingers and stuttered. There was no behavior problem for 112 $(69,1 \%)$ children. Of the patients, $47(29 \%)$ had received pharmacologic treatment in any period for the complaint, while 115 (71\%) had not. Among 
pharmacologic treatments administered, lactulose was in first place at $25,9 \%(n=42)$.

When trigger causes of the complaints were investigated, it was concluded that 10 cases $(6,2 \%)$ had begun school, $8(4,9 \%)$ had siblings born, 6 $(3,7 \%)$ had moved, $2(1,2 \%)$ had begun school and had a sibling born, $2(1,2 \%)$ had parents divorce, 1 $(0,6 \%)$ had lost a relative and $1(0,6 \%)$ was affected by the behavior of a cartoon character. For 132 cases $(81,6 \%)$, no trigger cause could be identified.

\section{Discussion}

Constipation is a defecation disorder commonly observed in the childhood period. In the literature, there are studies showing no difference in constipation incidence between the genders, in addition to studies showing higher incidence in male or female genders (Ip et al., 2005; Sarı and Dogan, 2012, Soylu, 2013). In our study, 62,3\% of cases were girls. Constipation is commonly observed in children from two-four years when toilet training is given (Rasquin et al., 2006; Afzal et al., 2011). When the age distribution of our patients is examined, the constipation complaint was most common in children from one month to three years of age $(53,1 \%)$, with the mean age of toilet training two years. Our findings comply with the literature.

Chronic constipation is defined as hard and painful defecation for at least two months along with defecation frequency of less than three times per week. As families do not know for definite when constipation begins, this duration is assessed as shorter than two months (acute) and longer than two months (chronic). Accordingly, 61,7\% of our cases had duration longer than two months and chronic constipation. Constipation is a situation that causes growth development delays (Guideline, 2006). The study by Sarı and Dogan (2012) found this rate was $17,2 \%$, while Sanll et al. (2014) found this rate was $10 \%$. In our study, development delay was present in $22,8 \%(n=37)$ of cases.

There are studies showing children who begin supplementary feeding early have a higher tendency toward constipation (Cumingham et al., 2001; Coughlin, 2003). Of our patients, 56,2\% ( $n=91)$ had begun supplmentary food early. High-fiber nutrition and enough fluid intake is recommended to prevent constipation (Weber et al., 2014). A study assessing nutritional content observed most cases with constipation had insufficient fiber content and fluid intake in diet
(Sanl1 et al., 2014). In our study, similarly, $72,2 \%$ of cases had insufficient nutritional fiber and $84,5 \%$ had insufficient fluid intake.

Constipation is accompanied by symptoms like abdominal pain, bleeding while defecating and abdominal distension. In the literature there are studies with rates of $12,2 \%$ and $66 \%$ for abdominal pain (Dogan et al., 2005; Sahin et al., 2014). In our study, $30,1 \%$ of cases had abdominal pain complaints. A study by Dogan et al. (2005) found the incidence of bleeding with defecation was $15 \%$, while the abdominal distension rate was $2,9 \%$. We found the incidence of bleeding while defecating was $9,8 \%$, with abdominal distension rate of $6,7 \%$. The differences in these rates may be due to differences in the study populations and the definitions of patient complaints.

Constipation being present in family members for more than $40 \%$ of children with constipation and constipation incidence being 6 times greater in single-egg twins compared to double-egg twins leads to the consideration of genetic tendency (Altaf and Sood, 2008). Soylu (2013), in a study of 355 patients, found family constipation history for $41 \%$. In our study this rate was similar at $39 \%$.

In $95 \%$ of patients with constipation, no organic cause can be identified in the etiology. This situation is called functional constipation (Baker et al., 1999). Dogan et al. (2005) in a study of 269 patients, found the functional constipation rate was $91,4 \%$. Soylu (2013) identified this rate as $91 \%$. In our study, the functional constipation rate was identified as $90,1 \%$, with hypothyroidism, anal stenosis and medication use first place among organic constipation causes with equal incidence of $1,9 \%$.

It is reported that in children with constipation and no anatomic or neurologic problems, urinary tract infections (UTI) may be observed (Mohkam, 2013). Two different studies found the UTI incidence rates were $8 \%$ and $9 \%$ among children with constipation (Loening, 1993; Sahin et al., 2014). In our patients, we found a similar rate of $13 \%$.

It is stated that children with constipation may experience a range of behavior problems due to not coping with this problem and internalizing the problem. Among these problems, the most common is biting fingernails (Dijk et al., 2007). A study by Savaser et al. (2011) found $17,1 \%$ of cases bit their nails. Among our cases, 30,9\% $(n=50)$ had behavior problems and nail-biting was first place at $17,3 \%$ $(n=28)$ in accordance with the literature. 
The first stage of treatment for constipation is balanced nutrition with sorbitol-rich fruit, sufficient fiber and fluids and urination training for those who are toilet-trained. If there is no response, medical treatment may be arranged (Dogan et al., 2005). For medical treatment, the most commonly chosen medication is lactulose 13. In our study, lactulose was the most commonly chosen medication for $25,9 \%$ of cases given medical treatment.

\section{Conclusion}

Constipation is a complaint with no gender difference that may be seen in all age groups and frequently has chronic progression. Among important organic causes of constipation that require research are hypothyroidism, anorectal anomalies, medications causing constipation, Hirschprung disease, hypopotassemia, hypercalcemia and vitamin D intoxication. The majority of cases have functional constipation, with early supplementary food, and lack of care about sufficient fiber and fluid intake causing this situation. To prevent constipation and to ensure treatment success for patients, the importance of focusing on these controllable risk factors should be explained to parents. Additionally, due to the presence of comorbid situations like urinary tract infection and behavior problems which may accompany constipation, constipation treatment should be completed in multidisciplinary fashion.

Ethics Committee Approval: Ethics committee approval was received for this study from Clinical Research Ethics Committee of Ordu University. (Decision Number: 2019-22)

Peer-review: Externally peer-reviewed.

Author Contributions: Concept-E.Y.E.; DesignE.Y.E., O.Y.; Supervision-E.Y.E., O.Y.; MaterialsE.Y.E., O.Y.; Data Collection and/or ProcessingE.Y.E., O.Y.; Analysis and/or Interpretation-O.Y.; Literature Review- E.Y.E.; Writing-E.Y.E.; Critical Review- O.Y.

Acknowledgements:

Conflict of Interest: No conflict of interest was declared by the authors.

Financial Disclosure: The authors declared that this study hasn't received no financial support

\section{Kaynaklar}

Afzal NA, Tighe MP, Thomson MA. Constipation in children. Ital J Pediatr 2011;37:28.

Altaf MA, Sood MR. The nervous system and gastrointestinal function. Dev Disabil Res Rev 2008;

14:87-95.

http://dx.doi.org/10.1002/ddrr.15

PMid:18646012.

Baker SS, Liptak GS, Colletti RB, Croffie JM, Di Lorenzo C, Ector W, et al. Constipation in infants and children: evaluation and treatment. J Pediatr Gastroenterol Nutr 1999;29(5):612-26.

Benninga MA. Children with constipation: What happens to them when they grow up? Scand $\mathbf{J}$ Gastroenterol 2004;39(241):23-6.

Constipation Guideline Committee of the North American Society for Pediatric Gastroenterology, Hepatology and Nutrition. Evaluation and treatment of constipation in infants and children: recommendations of the North American Society for Pediatric Gastroenterology, Hepatology and Nutrition. J Pediatr Gastroenterol Nutr 2006;43(3):1-13.

Coughlin EC. Assessment and Management of Pediatric Constipation in Primary Care. Pediatr Nurs 2003;29(4):296-301.

Cunningham C, Taylor HG, Minich NM, Hack M. Constipation in very-low-birth-weight children at 10 to 14 years of age. J Pediatr Gastroenterol Nutr 2001;33(1):23-7.

Dijk M, Benninga MA, Grootenhuis MA, Nieuwenhuizen AMO, Last BF. Chronic childhood constipation: A review of the literature and the introduction of a protocolized behavioral intervention program. Patient Educ Couns 2007;67:63-77.

Dogan Y, Erkan T, Ergul Y, Cokugras FC, Kutlu T. Retrospective analysis of the cases with complaint of constipation. Turkish Archives of Pediatrics 2005;40:23-7.

Hyman PE, Milla PJ, Benninga MA, Davidson GP, Fleisher DF, Taminiau J. Childhood functional gastrointestinal disorders: neonate/ toddler. Gastroenterology 2006;130(5):1519-26.

Ip KS, Lee WT, Chan JS, Young BW. A communitybased study of the prevalance of constipation in young children and role of dietary fibre. Hong Kong Med J 2005;11(6):431-6.

Kasirga E. Chronic Constipation and Nutrition. The Journal of Current Pediatrics 2007;5:113-8. 
Loening-Baucke V. Constipation in early childhood: patient characteristics, treatment, and longterm follow up. Gut 1993;34(10):1400-4.

Mohkam M. Voiding dysfunction in children with chronic functional constipation. Iran J Kidney Dis 2013;7(5):336-8.

Rajindrajith S, Devanarayana NM. Constipation in children: novel insight into epidemiology, pathophysiology and management. J Neurogastroenterol Motil 2011;17(1):35-47.

Rasquin A, Di Lorenzo C, Forbes D, Guiraldes E, Hyams JS, Staiano A, et al. Childhood functional gastrointestinal disorders: child/adolescent. Gastroenterology 2006;130(5):1527-37

Sahin S, Gulerman F, Koksal T, Koksal AO. Evaluation of Cases with Chronic Constipation in Children. Turkish Journal of Pediatric Disease 2014;8(3):117-23.

Sar1 Y, Dogan Y. Evaluation of Clinical Symptoms, Etiological Factors and Results of Follow up in Cases with Constipation Complaint. Firat University Journals of Health Sciences 2012;26(3):121-5.

Savaser S, Kurt AS, Mutlu B, Filiz G, Aydogar N. Characteristics of Children Admitted to Hospital for Constipation. The Journal of Current Pediatrics 2011;9(3): 103-9.
Soylu OB. Clinical Findings of Functional and Secondary Constipation in Children. Iran $\mathbf{J}$ Pediatr Jun 2013;23(3):353-6.

Taitz LS, Wales JKH, Urwin OM, Molnar D. Factors associated with outcome in management of defecation disorders. Arch Dis Child 1986;61(5):472- 7.

Weber TK, Toporovski MS, Tahan S, Neufeld CB, de Morais MB. Dietary fi ber mixture in pediatric patients with controlled chronic constipation. $\mathrm{J}$ Pediatr Gastroenterol Nutr 2014;58(3):297-302. 